\title{
Experiências formativas do outro diferente em ambientes de amizade*
}

\section{Formation experiences of different other in environments of friendship}

\author{
Roque Strieder** \\ Universidade do Oeste de Santa Catarina \\ Fabiana Herbert*** \\ Universidade do Oeste de Santa Catarina
}

Resumo $\mathrm{O}$ artigo investiga possibilidades de se firmarem experiências formativas envolvendo as dimensões da amizade e as vivências na amizade, como dinâmicas potencializadoras do reconhecimento do outro. Considera as relações pedagógicas, visando à homogeneização, como portadoras do risco de submeter e excluir o outro e o diferente. Reconhece a necessária prudência diante da complexidade e das dificuldades históricas de compreensão do outro. $\mathrm{O}$ estudo tem como base a buscagem em referenciais teóricos e entende que a vivência na amizade permite a construção de visões positivas de mundo, de si e do outro como seres humanos singulares e diversos. A convivência na amizade como um com-sentir contempla cenários de respeito à alteridade, um respeito que passa pela descoberta de si e do outro como exercício dessa convivência.

PALAVRAS-CHAVE: Escola acolhedora; O outro; A amizade.

Abstract The article investigates possibilities of establishing formative experiences involving the dimensions of friendship and experiences in friendship as a dynamic that makes possible the other's recognition. It considers the pedagogical relations, aiming to homogenization as the risk carters of submitting and excluding the other and the different. It recognizes the prudence required in face of the complexity and historical difficulties in understanding the other. The study is based on the search for theoretical references and it understands that the friendly experience allows the construction of world positive visions from ourselves and from others considering us as unique and diverse human. The coexistence in friendship as a consent (feel with) includes scenarios with respect to otherness, a respect that goes by the self and the other's discovery as an exercise of this living.

KEYWORDS: Welcoming school; The other; The friendship.

\footnotetext{
* Artigo resultante de pesquisa desenvolvida com apoio do Programa PIBIC/CNPq.
} 


\section{Considerações iniciais}

Compreender melhor a concepção de diferente ou da diferença se alarga no contexto da diversidade. Isso significa reconhecer os limites das concepções homogeneizadoras para, então, entender a inesgotável riqueza das diferenças. Visualizar o significado das individualidades de cada ser humano, em cada momento e cada fenômeno, permite experiências e ações distintas das que ao "atender demandas universais, negligenciam as particularidades dos contextos e sacrificam a alteridade" (HERMANN, 2010, p. 132). A insistência em mecanismos de homogeneização e de afirmações universais, excluindo o estranho, o diferente e o irracional, conserva os seres humanos em relações de frieza e distância. A trama dessa frieza encontra suporte, na atualidade, na lógica do paradigma tecnocientífico que enclausura o mundo, tornando-nos cegos ao ser humano. Esse pensamento que sustenta e emana da tecnociência, absolutizada como razão única, se faz acompanhar de cegueiras e de omissões que negligenciam a dimensão humana.

O não reconhecimento da redução linear e dos limites dos pressupostos universais, juntamente com o não reconhecimento das cegueiras que emergem do racionalismo tecnocientífico, são graves empecilhos diante dos imperativos contemporâneos da flexibilização sonhando a celebração da diferença e da diversidade.

Continuamos envoltos por normativos, fundamentando as comparações entre as pessoas com o objetivo de evidenciar desvios para, então, definir destinos via reforço das noções de normalidade e anormalidade. Insistimos na concepção de que o dito normal é aquele com capacidade para moldar-se de acordo ao modelo e, diferente, como anormal é considerado aquele que não se enquadra no modelo.

Em alguns momentos as políticas de inclusão, no âmbito escolar ou social, formuladas e executadas no país, passam a margem ou ignoram as diferenças e a diversidade. Significa que, ao invés de promoverem uma educação inclusiva, em âmbito escolar e, voltada para todos, podem reforçar a exclusão dos diferentes. Apesar do esforço, em termos de acesso universal das crianças na escola, persistem as possibilidades de fracasso. Freitas (2007) denomina esse fenômeno do fracasso escolar institucionalizado como "exclusão branda", ou seja, usar como "estratégia, crianças nas trilhas de progressão continuada, diferenciadas no interior da própria escola [...] reforça as práticas de interiorização da exclusão" (2007, p. 41). E, sustenta Freitas, esse fracasso continua sendo atribuído a condições pessoais e sociais dessas crianças, portanto, de sua exclusiva responsabilidade.

Para Veiga-Neto e Lopes (2007, p. 03), apesar da eventual existência de caráter humanista ou inovador, "as políticas de inclusão escolar funcionam como um poderoso e efetivo dispositivo biopolítico a serviço da segurança das populações”.

Em outras frentes de reflexões, feitas por educadores e outros intelectuais, o desafio do acesso escolar é concebido como inerente e complementar à qualidade educacional para todas as crianças. Para eles, a educação escolar contempla espaços sociais, reconstruídos historicamente, portanto, não mais em contextos de prevalência 
do natural. Isso abre diferentes possibilidades diante das tradicionais práticas escolares da homogeneização, da categorização e da exclusão, problematizando-as radicalmente.

No rol dessas reflexões começa a fazer sentido a necessidade de superar a concepção de escola "como o lugar privilegiado para a invenção e experimentação dos novos saberes e para a intervenção do Estado e de suas políticas que visam à segurança da população" (VEIGA-NETO e LOPES, 2007, p. 08).

Mesmo assim, estamos distantes tanto em relação a perspectivas consensuais no plano teórico quanto no campo das políticas públicas e, também, no campo das práticas pedagógicas. Uma situação que precisamos reconhecer como conveniente, pois a história nos ensina que soluções apressadas e definitivas tendem, muito cedo, a mostrarem suas insuficiências e fragilidades, diante da dinâmica presente em sociedades, consideradas cada vez mais complexas.

Não será pela lógica dos ativismos cegos que o sonho de uma educação para todos e com qualidade singular para cada um tem melhores chances de realização. É fundamental o universo da reflexão e da compreensão. São elas que permitem fazer aflorar ambivalências e contradições dos debates e abrir oportunidades para problematizar questões antropológicas, culturais, sociais, políticas e pedagógicas da educação com qualidade para todos, na singularidade de cada um. Pela dinâmica das reflexões, fundamentadas no diálogo, é possível perceber características e visualizar implicações que permitem avançar em direção às práticas educativas menos instrumentalizadoras.

É nessa dinâmica de reflexões e de aberturas para o diálogo que acenamos para a possibilidade de que experiências formativas para e com o outro diferente, num cenário de amigos e envolto em ternura, podem tornar-se significativas. $\mathrm{O}$ cuidado de si e do outro, reconhecidos em sua legitimidade existencial, passa pela consciência de pertença a um mundo natural, no qual a amizade significa aceitação das diferenças e da diversidade.

Assim, e com base no anteriormente referenciado, o estudo tem como objetivo investigar se e como experiências formativas, envolvendo as dimensões da amizade e as vivências na amizade, permitem potencializar o reconhecimento da interdependência entre si e o outro para vivenciar a aceitação desse si e do outro. Trata-se de uma buscagem em referenciais teóricos, uma atividade de pesquisa colaborativa, pois, no encalço de passos seguidos por outros pensadores, nos beneficiamos de seus trabalhos, de seus princípios e, porque não dizer, de suas práticas.

Experiências formativas, na dimensão da ternura e convividas em amizade, valorizam as inúmeras interfaces dessa mesma convivialidade como coexistência do autorrespeito e do respeito ao outro. Fazê-lo requer participação e colaboração como fundamentos da compreensão da ternura e da amizade, como inerentes espontâneos do ser e do fazer pedagógico.

Acreditamos que a vivência da amizade, no conforto da ternura, permite a construção de visões positivas de mundo, de si e do outro como ser singular e diverso. Fazê-lo, com esse espírito de abertura, requer, simultaneamente, respeito e desapego, respeito ao dizer do outro e desapego ao seu próprio dizer. 
A convivência como um com-sentir (AGAMBEN, 2010) contempla cenários de respeito à alteridade, um respeito que passa pela descoberta de si e do outro como exercício de convivência.

\section{Os oscilantes cenários educativos}

O rompimento com os compromissos humanizadores, de legitimidade do outro e do desejo de sua presença radicaliza e expõe, para além do normal, a violência e a agressividade visíveis na delinquência, na violência urbana, na violência institucional, nos atos de terrorismo, nos enfrentamentos étnicos, religiosos, entre outros.

Nesse contexto e diante da exigência de cumprir expectativas pré-definidas provindas, sobretudo, do mercado de trabalho e demandas profissionais, a dinâmica formativa não consegue desenvolver a potencialidade do educando, como ser humano capaz de questionar e significar o sentido do existir.

Essa crise formativa, também uma crise existencial, gera, na afirmação de Fernández (2010, p. 47) o "desencanto do ser humano, a sensação de vazio interior ou aborrecimento metafísico, a grande falta de motivações que ocasiona a fadiga de viver, o aumento da ansiedade e da angústia traduzido em estresse e outras enfermidades". Para Fernández, a instrumentalização e o utilitarismo, juntamente com a perda do horizonte de crenças, resultam na incapacidade de visões e opções de sentido mais profundas sobre a riqueza das diversas culturas e das diversas individualidades. A sistemática formativa, que não se despede das ameaças da racionalidade meramente instrumental, nega, também, o desenvolvimento da capacidade da aceitação e acolhida do outro, como outro legítimo em sua singularidade.

Diante desse conturbado momento histórico e formativo, que afeta a vida em todas as suas dimensões, torna-se crucial o desafio de reequilibrar os processos formativos. Um desafio existente em potencial e, pelo qual a violência, os medos e os ódios, bem como as cegueiras de afeto, são "elementos inteligentes e perceptivos da personalidade que estão muito estreitamente vinculados às crenças e se modificam quando estas se modificam" (NUSSBAUM, 2003, apud, HERMANN, 2010, p. 102). Considerando a potencialidade mutável de atitudes, se em paralelo acontecerem as mudanças nas crenças, a superação do universo preconceituoso permite sonhar uma sociedade a ser construída tendo como base a confiança básica e relações interpessoais sadias. Para Fernández (2010, p. 45), essa mudança de mentalidade, capaz de gerar formas diferentes de estar no mundo, implica num processo de educação das novas gerações baseado nas relações de ternura. Mas, ela questiona: "É coerente num mundo ferido pela violência, a injusta distribuição dos bens, o abuso do poder e a incapacidade de relacionar-nos como uma fraternidade humana, a pretensão de pôr no centro de nosso discurso sobre Deus, sobre o ser humano e sobre o encontro entre ambos, algo como a ternura?".

Para Rocha Filho et al. (2007) a ternura do afeto, além de assegurar a integridade biológica, firma a interdependência e é característica da cognição humana.

É cada vez mais importante assumirmos que dependemos afetivamente uns dos outros, assim como dos demais seres vivos e do 
ar, da água, da terra e da luz, até mesmo para assegurarmos nossa integridade biológica [...] o que caracteriza a cognição humana, é justamente, a afetividade presente nas manifestações de convivência com outras pessoas. (ROCHA FILHO et al, 2007, p. 31-32).

Numa outra dimensão da dinâmica escolar, chama-se a atenção para a reflexão filosófica, pedagógica e educacional, para que, reorientada assuma como preocupação central os contextos e as dificuldades da vida relacional, cultural e produtiva dos seres humanos. É nesse sentido que Martha Nussbaum considera que

Quem se dedica a escrever ou ensinar filosofia é uma pessoa afortunada como poucos seres humanos o são, ao poder dedicar sua vida à formulação dos pensamentos e sentimentos mais profundos acerca dos problemas que mais a têm motivado e fascinado. Mas esta vida estimulante e maravilhosa é também parte do mundo em seu conjunto, um mundo em que a fome, o analfabetismo e a doença são a sina diária de grande parte dos seres humanos que ainda existem, assim como causas da morte de muitos que não existem ainda. Uma vida de ociosa e livre expressão é, para a maioria da população mundial, um sonho tão distante que raramente se chega a conceber. $\mathrm{O}$ contraste entre essas duas imagens da vida humana conduz a uma pergunta: Que direito tem alguém de viver num mundo feliz, que pode expressar-se livremente, enquanto exista o outro mundo e alguém seja parte dele? (NUSSBAUM, 2003, apud HERMANN, 2010, p. 91-92).

Entendemos que nem Fernández, nem Rocha Filho ou Nussbaum estejam propondo algo meramente romântico, mas sim, desafios que podem tornar visível uma nova sensibilidade para tornar significativa a exceção, como preocupação com aqueles não cobertos pelos normativos, reinaugurando a diversidade da vida, a diversidade das realidades, das culturas e dos diferentes grupos humanos. Um esforço complexo para compreender em profundidade os limites e as potencialidades do entendimento humano. Então, nada mais significativo do que considerar as necessidades básicas, sejam elas biológicas ou psicoafetivas da existência humana, para entender as experiências humanas vividas como ser humano.

Kant, em Sobre a Pedagogia (1996), considera o ato pedagógico como uma ação capaz de garantir que os interesses do ser humano estejam voltados a sua subjetividade, à intersubjetividade e ao bem universal. Afirma que a própria natureza dispôs nos seres humanos sementes de humanidade. Sementes que contém o seu destino, mas é compromisso da educação cultivar essas sementes para que germinem e se desenvolvam nos contextos do bem e deem frutos de bondade humana.

Significa dizer que o desafio das experiências formativas é o de esperançar por melhores condições de vida para a humanidade, a ser iniciada no presente, forte e profunda o suficiente para que se estenda ao futuro. Se, no contexto do chamado social existe feiura, corrupção, mentira e indiferença, as ações pedagógicas e educativas precisam contribuir para sua superação. É nesse sentido que Kant escreve "o estabelecimento de um projeto educativo deve ser executado de modo cosmopolita" (KANT, 1996, p. 23), ou seja, a educação objetiva, como finalidade, criar o bem geral e projetar uma humanidade melhor. Reiteramos que essa humanidade melhor pode realizar-se tendo a amizade como base da experiência formativa. 


\section{Vivência da amizade como experiência formativa}

No desenvolvimento do pensamento ocidental, a amizade esteve, desde o princípio, vinculada estreitamente à filosofia e porque não dizer à educação. A expressão filosofia traz, em seu prefixo, o philos, o amigo. Em "Ética a Nicômaco", Aristóteles reconhece que a amizade é uma virtude extremamente necessária à vida. Mesmo dispondo de bens materiais, saúde e poder, para uma realização plena, ainda nos faltaria o essencial: a amizade. Aristóteles entendia que justiça e amizade, apesar de possuírem os mesmos fins, a amizade é superior à justiça. Justifica ser a justiça utilizada para contornar nossos atos em relação ao próximo que não conhecemos e que, junto aos amigos não precisamos de justiça, uma vez que a natureza da amizade nos é completa, significando uma autêntica forma de justiça, o que implicaria uma humanidade melhor.

Escreve Aristóteles (2002, p. 173): “A amizade não é apenas necessária, mas também nobre, pois louvamos os homens que amam os seus amigos e considera-se que uma das coisas mais nobres é ter muitos amigos. Ademais pensamos que a bondade e a amizade encontram-se na mesma pessoa".

Se amizade é virtude e é nobre, então em cenários de diversidade e das diferenças ela se torna importante para a convivência humana. A sua não efetivação exige que as relações intersubjetivas com os semelhantes, visando o bem comum, precisam pautar-se em direitos e deveres. No contexto da civilização grega, em razão do culto ao corpo, a intolerância se perpetuava pela prática de atrocidades contra os seres humanos com limitações físicas, portanto, fora da normalidade. Em nome da contemplação do belo e da normalidade, eram legitimados afogamentos, assassinatos, bem como a ação de esconder as crianças, consideradas fora dos padrões do belo físico.

Na longa Idade Média, o estigma da intolerância é ainda mais violento, uma vez que se partia do princípio de que a deficiência era uma marca do "maligno" e, como tal, devia ser extirpada via uso de meios dos mais degradantes, como torturas e crueldades para sacrificar ou afastar do convívio social as pessoas fora do padrão de normalidade.

$\mathrm{Na}$ modernidade, a referência ao normal implica na necessidade da criação da categoria do anormal, visando estabelecer um antagonismo normal versus anormal. Isso significa a necessidade da existência do anormal para se tomar o normal como referência. Assim, para Foucault (1996, p. 114), “a fábrica não exclui os indivíduos; liga-os a um aparelho de reprodução. A escola não exclui os indivíduos; [...] ela os fixa a um aparelho de transmissão do saber. O hospital psiquiátrico não exclui os indivíduos; liga-os a um aparelho de correção, [...] de normalização dos indivíduos". Ou seja, a finalidade fundamental dessas instituições é "fixá-los a um aparelho de normalização". Em outro momento, escrevendo sobre "Os anormais", Foucault (2013) afirma que a figura do anormal pode ser abordada a partir de três elementos: o monstro humano, o indivíduo a corrigir e o onanista. ${ }^{1}$ Em Vigiar e Punir, Foucault (1993) afirma que a partir do início do século XIX, a questão da norma passa a fazer parte da sociedade disciplinar. O exercício do poder disciplinar, baseado em técnicas disciplinares, será usado para determinar o louco e o são, o perigoso e o inofensivo, o normal e o anormal. 
As técnicas disciplinares foram criadas para tentar normalizar os corpos das pessoas. A partir da disciplina normalizadora, os indivíduos serão corrigidos para que todos sejam parecidos, tenham os mesmos comportamentos, os mesmos hábitos e a mesma capacidade intelectual. Para Foucault:

Em certo sentido, o poder de regulamentação obriga à homogeneidade; mas individualiza, permitindo medir os desvios, determinar os níveis, umas às outras. Compreende-se que o poder da norma funcione facilmente dentro de um sistema de igualdade formal, pois dentro de uma homogeneidade que é a regra, ele introduz, como um imperativo útil e resultado de uma medida, toda a gradação das diferenças individuais. (FOUCAULT, 1993, p. 164).

A norma e o poder da norma são utilizados para identificar os sujeitos homogeneizados, os adequados à norma e os diferentes, ou seja, os anormais.

Diante desse contexto histórico e atual, não favorável ao outro diferente, enquanto outro e diferente, anseia-se por uma metamorfose educativa que permita a vivência de experiências formativas de amizade como "uma concepção enraizada nos contextos plurais do mundo da vida, que se vê diante da alteridade, num eu que é atravessado pelo outro" (HERMANN, 2011, p. 140).

Entendemos que a educação, seja a familiar ou a oferecida pelo Estado, via escola, precisa legitimar a insuficiência da lógica de processos educacionais balizados pela ideologia utilitarista e de submissão do outro. Diante do meramente instrumental é preciso reconhecer um diferente potencial existente em crianças e adolescentes, no ser humano, enfim. Potencial que possibilita um pleno desenvolvimento da capacidade ética para, então, compreender a importância do amigo, seja ele um outro estranho, "normal" ou "anormal", primando pela amizade porque é capaz de superar a "exclusão e a apropriação" (HERMANN, 2011, p. 145). Experiências formativas de amizade permitem ações de forma fraterna e solidária, o que significa acolher e não somente incluir. São experiências formativas que possibilitam a convivência e a acolhida de todos, mesmo dos feridos pelo analfabetismo afetivo (RESTREPO, 1998). São as experiências de amizade, como experiências formativas que permitem abraçar a cada ser humano, muitas vezes cansado e solitário, mas extremamente carente de afetividade e amor.

Amizade, configurada por Aristóteles, como escreve Lara:

De maneira geral, a amizade ( $\varphi \imath \lambda i ́ a)$ é a comunidade de duas ou mais pessoas ligadas por afeto e atitudes concordantes voltadas para o bem. Aristóteles [...] define a amizade como virtude e hábito, não como condicionamento, mas como disposição de caráter, disposição ativa de empenho da pessoa ao bem. Uma vez que, a ética visa à ação com moderação, predispondo o caráter a excelência moral, a apreciar o que é certo evitando os erros 'pois afirmamos que a finalidade suprema, e o principal empenho desta ciência é infundir um certo caráter nos cidadãos - por exemplo, torná-los bons e capazes de praticar boas ações' [...] a amizade firma um vínculo social, como virtude política, lembrando que o homem não pode desenvolver as virtudes nem a felicidade sem a sociedade, por duas razões: sem a 
sociedade não sobreviveria uma vez que em princípio precisaria dos bens fundamentais, e sem as leis sociais nunca alcançaria as virtudes. (LARA, 2009, p. 91).

Também é relevante evidenciar, como fundamental para a realização de experiências formativas, vivenciando experiências de amizade em ambientes escolares e projetando a visão de singularidade e da diversidade, a noção de amigo nos termos refletidos por Agamben (2010). Agamben também destaca a profunda intimidade entre filosofia e amizade, a tal ponto que o philos integra a filosofia. Alerta que essa grande proximidade pode, também, impedir uma realização efetiva da amizade.

Agamben (2010, p. 81-82) concebe suas reflexões usando como referência a Ética a Nicômaco, de autoria de Aristóteles, e as reflexões de Jacques Derrida "Políticas da Amizade". Discute a polêmica de frases atribuídas a Aristóteles: "ó amigos, não há amigos", negando a amizade, e: "aquele que tem (muitos) amigos não tem nenhum amigo", reafirmando a importância da amizade e, ao mesmo tempo, a permissão de certa dose de desconfiança em relação aos amigos. Uma das preocupações de Derrida, ao refletir a concepção de amizade em Aristóteles, é a relação com o outro a partir da concepção de amizade como sendo "uma alma em dois corpos" (Apud CAMPOS, 2008, p. 45).

Derrida reflete uma passagem em Cícero na qual este afirma "Aquele que tem sob os olhos um verdadeiro amigo tem diante de si sua própria imagem ideal” e questiona:

[...] o amigo, é o mesmo ou é o outro? Cícero prefere o mesmo [...] Ora, segundo Cícero, nós projetamos ou reconhecemos no verdadeiro amigo nosso exemplar, nosso duplo ideal, nosso outro "nós mesmos", o mesmo que nós. Pois nós o olhamos a olhar-nos e desse modo olhar a si mesmo, pois nós o vemos guardar nossa imagem nos seus olhos, na verdade nos nossos. A sobrevida então é esperada, desde já iluminada, senão assegurada, por esse Narciso que sonha com a imortalidade. Do outro lado da morte, o porvir absoluto recebe assim sua luz estática. Ela somente aparece depois desse narcisismo e segundo essa lógica do mesmo. (DERRIDA, apud CAMPOS, 2008, p. 45).

Então, na amizade como experiência formativa, pode-se entender, como escreve Hermann, a partir de Gadamer, que "o reconhecimento do outro surge no próprio diálogo e a subjetividade constitui-se na intersubjetividade" (HERMANN, 2011, p. 145).

Segundo Agamben, amizade tem a ver com proximidade que independe do ver-se reciprocamente e, por isso, dispensa qualquer necessidade de representação. Reconhecer um outro "significa não reconhecê-lo como 'algo' [...] a amizade não é uma propriedade ou uma qualidade de um sujeito" (2010, p. 85). Ainda para Agamben, a sensação da existência, uma sensação especificamente humana, se realiza no "comsentir' a existência do amigo" (p. 89). Assim, o amigo é "um outro si" uma "alteridade imanente na 'mesmidade', um tornar-se outro do mesmo" (p. 90). 
Com base na "Ética a Nicômaco" de Aristóteles, Agamben entende que o "com-sentir" é partilhar com alguém - um outro como amigo - em convivência, ou seja, "também para o amigo se deverá com-sentir que ele existe, e isso acontece no conviver (syzen) e no ter em comum (koinonein) ações e pensamentos. Nesse sentido, dizse que os homens convivem e não, como para o gado, que condividem o pasto" (p. 91).

Apostamos que, em ambientes escolares e como ação educativa, seja possível a vivência da experiência dessa amizade, ultrapassando a tradicional necessidade de submeter o outro. Uma amizade, pela qual o outro como amigo, crianças e educadores 'com-sentindo', poderia admitir que ela (a amizade) é muito mais significativa do que o partilhar de informações lógicas e sistematizadas, com abertura de sensibilidade ao horizonte do outro como uma repartição do "próprio fato de existir, a própria vida". (AGAMBEN, 2010, p. 92).

Segundo Aristóteles, a amizade é uma emoção que nos abre para a possibilidade de sentir, de com-sentir. Implica uma disposição do eu interior, capaz de proporcionar a virtude. Trata-se de proximidade, o que equivale a dizer: andar juntos.

\begin{abstract}
A amizade perfeita é a existente entre as pessoas boas e semelhantes em termos de excelência moral; neste caso, cada uma das pessoas quer bem à outra de maneira idêntica, porque a outra pessoa é boa, e elas são boas em si mesmas. Então as pessoas que querem bem aos seus amigos por causa deles são amigas no sentido mais amplo, pois querem bem por causa da própria natureza dos amigos, e não por acidente; logo, sua amizade durará enquanto estas pessoas forem boas, e ser bom é uma coisa duradoura. (ARISTÓTELES, 2002 p. 260-261).
\end{abstract}

Como fundamento da concepção de Aristóteles sobre a amizade, está a possibilidade de aproximar-se do outro e compartilhar o desejo de fazer bem a esse outro. $\mathrm{O}$ desejo de fazer bem ao outro oportuniza uma humanidade melhor e, quem sabe, esse com-sentir que o outro existe, permitindo-lhe a vivência de experiências de amizade, como desafio formativo, realize os estados de paz, sonhados por Ricoeur (2006). Estados de paz nos ambientes escolares, como uma acolhida do outro diferente (não somente do próximo) e, como acredita Ricoeur, tendo a agápe como fonte de emulação. Uma agápe que permite suspender a disputa, a rivalidade e a competição instrumentalizadora, uma forma de esquecer as ofensas, não para afastá-las ou reprimi-las, mas “deixá-las ir”, ou seja, perdoar (RICOEUR, 2006, p. 235). Na agápe, escreve Ricoeur (2006, p. 236), “o próximo, não como aquele que está próximo, mas como aquele do qual nos aproximamos”.

Assim, consideramos que a convivência, como um com-sentir, contempla cenários de respeito à alteridade, um respeito que passa pela descoberta de si e do outro como exercício de convivência, como escreve Weil

Passando a descoberta do outro, necessariamente, pela descoberta de si mesmo, e por dar à criança e ao adolescente uma visão ajustada do mundo, a educação, seja ela dada pela família, pela comunidade ou pela escola, deve antes de mais nada ajudá-los a descobrir a si mesmos. Só então poderão, verdadeiramente, pôr-se no lugar dos 
outros e compreender as suas reações. Desenvolver esta atitude de empatia na escola é muito útil para os comportamentos sociais aolongo de toda a vida. (WEIL, 1993, p. 135-136).

Enfim, nossa aposta é que, numa escola acolhedora, o outro diferente é esse próximo do qual nos aproximamos, também envoltos em ternura e amizade. Isso requer não somente a dimensão da necessidade, mas também a dimensão do desejo.

Desejo de se aproximar, de realimentar o ambiente escolar com a vivência da amizade, para fazer de cada sala de aula um recanto de ternura. Poderemos ter, então, experiências formativas, não vinculadas ao dever ser, mas como expressão de sensibilidade para recriar-se recriando o outro, um encontro efetivo e espontâneo junto ao outro, como encontro de seres humanos, ao invés do encontro entre objetos instrumentalizados.

\section{Referências}

AGAMBEM, G. O que é o contemporâneo? E outros ensaios. Chapecó: Argus, 2010.

ARISTÓTELES. Ética a nicômaco, São Paulo: Martin Claret, 2002.

CAMPOS, N. F. A amicitia na obra politiques de l'amitié de Jacques Derrida. Anais XXIII SEC, Araraquara, p. 42-48, 2008. Disponível em: <http://portal.fclar.unesp.br/ec/BANCO DE DADOS/XXIII SEC/TEXTOS/ARTIGOS PDF/campos.pdf>. Acesso em: 24 out. 2012.

FERNÁNDEZ, N. M-G. É possível uma teologia da ternura? In: Perspectiva Teológica, ano XLII, n. 116 jan./abr, 2010.

FOUCAULT, M. Vigiar e punir: nascimento da prisão. 10. ed., Petrópolis: Vozes, 1993.

FOUCAULT, M. A verdade e as formas jurídicas. Rio de Janeiro: Nau, 1996.

FOUCAULT, M. Os anormais: curso no Collège de France (1974-1975). São Paulo: Martins Fontes, 2013.

FREITAS, L. C. Eliminação adiada: o ocaso das classes populares no interior da escola e a ocultação da (má) qualidade do ensino. Educação e Sociedade, 2007, v. 28, n. 100, p. 965-987.

KANT, I. Sobre pedagogia. Piracicaba: Unimep. 1996.

HERMANN. N. Autocriação e horizonte comum: ensaios sobre educação ético-estética. Ijuí: Unijuí, 2010.

HERMANN. N. Breve investigação genealógica sobre o outro. In: Educação e Sociedade, Campinas, v. 32, n. 114, p. 137-149, jan./mar., 2011. Disponível em: <http://www.cedes.unicamp.br>. Acesso em: 24 out. 2012.

LARA, R. O. A amizade na ética a Nicômaco, 2009. Dissertação (Mestrado em Filosofia) Universidade Estadual do Ceará, Ceará. Disponível em: <http://www.uece.br/cmaf/dmdocuments/ disาsertacao2009_amizade_etica_nicomaco.pdf >. Acesso em: 24 out. 2012.

RESTREPO, L. C. O direito à ternura. Petrópolis: Vozes, 1998.

RICOEUR, P. Percurso do reconhecimento. São Paulo: Loyola, 2006.

ROCHA FILHO, J. B.; SOUZA BASSO, N. R.; BORGES, R. M. R. Transdisciplinaridade: a natureza íntima da educação científica. Porto Alegre: EDIPUCRS, 2007. 
VEIGA-NETO, A.; LOPES, M. C. Inclusão e governamentalidade. In: Educação e Sociedade, v. 28, n.100. Campinas out. 2007. Disponível em: <http://dx.doi.org/10.1590/S010173302007000300015 >. Acesso em: 27, mai. 2014.

WEILL, P. A arte de viver em paz: por uma nova consciência, por uma nova educação. São Paulo: Gente, 1993.

\section{Nota}

${ }^{1}$ Onanista - palavra originária de Onã que, conforme relatado em Gênesis 38, 1-11, obrigado a casar com a esposa de seu irmão praticava o coito, ou seja, os espermatozoides eram ejaculados fora do corpo da mulher, resultando em desperdício. Normalmente é apresentado como sinônimo de masturbação masculina, por esta também implicar em desperdício de espermatozoides.

** Professor doutor da Universidade do Oeste de Santa Catarina, Joaçaba, Santa Catarina, Brasil.

*** Graduanda em Pedagogia pela Universidade do Oeste de Santa Catarina, Joaçaba, Santa Catarina, Brasil.

\section{Correspondência}

Roque Strieder - Universidade do Oeste de Santa Catarina, Campus de São Miguel do Oeste. Rua José Firmo Bernardi , 1591 Campus II. Flor da Serra, CEP: 89600-000 - Joaçaba, Santa Catarina, Brasil.

E-mail: roque.strieder@unoesc.edu.br - bibizinha.fabismo@hotmail.com

Recebido em 17 de julho de 2014

Aprovado em 18 de janeiro de 2015 